\title{
اتجاهات أولياء الأمور ومعلمي الصفوف الثلاث الأولى نحو استخدام التعليم عن بعد والتعليم التقليدي بالأردن (دراسة مقارنة)
}

\section{مروان عبدالله العوايشة}

جامعة البلقاء التطبيقية- الأردن

Mrwan84@bau.edu.jo 


\title{
اتجاهات أولياء الأمورومعلمي الصفوف الثلاث الأولى نحو استخدام التعليم عن بعد والتعليم التقليدي بالأردن (دراسة مقارنة)
}

\author{
مروان عبدالله العو ايشـة \\ جامعة البلقاء التطبيقية- الأردن \\ Mrwan84@bau.edu.jo
}

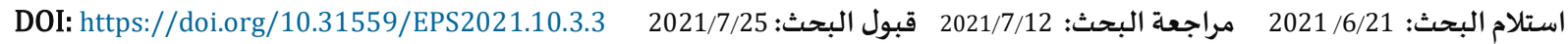

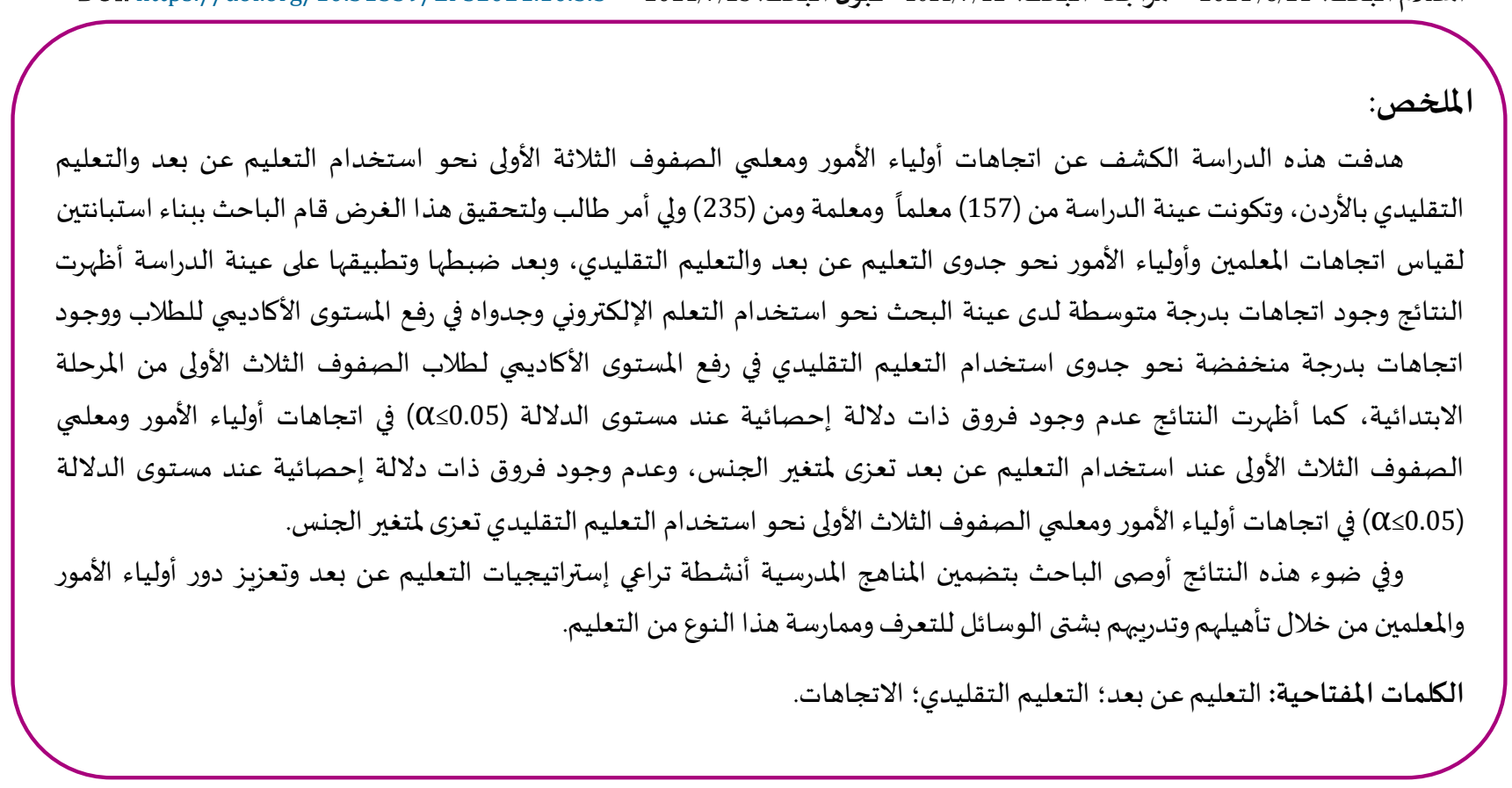

1. المقدمة:

يعد التعليم من المقومات الأساسية لحياة المجتمعات المعاصرة وذلك إلى جانب خدمات اجتماعية أخرى مثل السكن والصحة والأمن وغيرها،

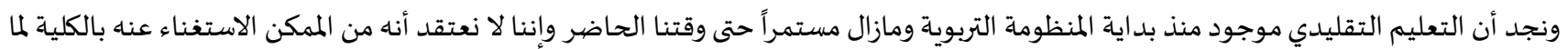

له من إيجابيات لا يمكن أن يتوفر لها بديل. (سامي، إيمان، 2019)

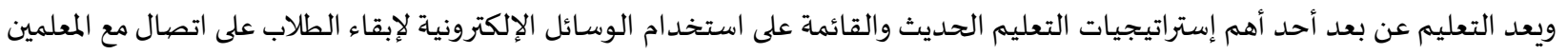

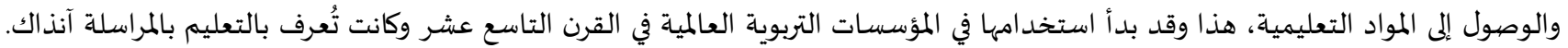
(فريق العمل، 2020) ولقد تم تأسيس أول إدارة مستقلة للتعليم بالمراسلة في جامعة شيكاغو عام 1892 م، وبذلك صارت الجامعة الأولى على مستوى العالم التي تعتمد التعليم عن بعد، فقد كان الطلاب يرسلون واجباتهم والوظائف بالبريد ثم يصححها المعلمون، ويعيدون إرسالها بالدرجات إلى الطلاب، وكان

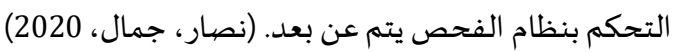


في هذه المرحلة التي يعاني بها العالم جراء جائحة كورونا، أصبحت استمرارية التعليم أكثر تحدياً للطلاب والمعلمين والمؤسسـات التربوية، وتعد هذه الجائحة تجربة حقيقية نحاول جميعاً التكّيف معها، وعلينا فقط تكرس الكثير من الجهود لتعزيز أساليب العمل والتواصل بهائ بين الطلاب والمعلمين بهدف استمرارية العملية التعليمية. (فريق العمل، 2020)

1.1. أهمية الدراسة:

يرى الباحث أن مقدار التعليقات على مواقع التواصل الاجتماعي الرافضة لفكرة التعليم عن بعد، وعن آثارها السلبية على المستوى الأكاديمي للطلاب، خاصة مرحلة الصفوف الثلاث الأولى، و صعوبة إيصال المعلومة إلى الأطفال في هذه المرحلة. لا سيما وأهها أهم مرحلة عمرية في حياة الطالب، فهي مرحلة تعلم الأحرف و تركيب الكلمات وأسـاسيات العد وغيرها ومن هنا ظهرهات المهات أهمية هذا البحث وهي " دراسة مقارنة لاتجاهات أولياء الأمور و معلهي الصفوف الثياه اهلاثة الأولى نحو استخدام التعليم عن بعد والتعليم التقليدي بالأردن.

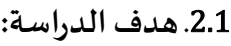

يهدف البحث الحالي إلى تعرف اتجاهات أولياء الأمور والمعلمين نحو الانتقال من التعليم التقليدي إلى التعليم عن بعد لطلبة الصفوف الثلاث

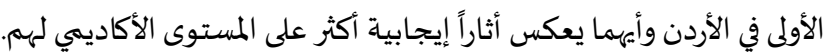

3.1. مشكلة الدراسة و أسئلتها: تتلخص مشكلة الدراسة بالإجابة عن السؤال التالي: ما اتجاهات أولياء الأمور ومعلمي الصفئوف الثلاثة الأولى نحو استخدام التعليم عن بعد والتعليم التقليدي بالأردن وتفرع عن هذا السؤال الأسئلة التآلية: 1. ما اتجاهات أولياء الأمور ومعلمي الصفوف والثفئلاث الأولى نحو استخدام التعليم عن بعد وقدرتهاته على إيصال المعلومة للطالب؟ 2. ما اتجاهات أولياء الأمور ومعلمي الصفوف الثلاث الأولى نحو استخدام التعليم التقليدي وقدرته على إيصال المعلومة للطالب؟

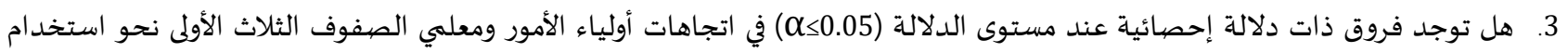
التعليم عن بعد تعزى لمتغير الجنس؟ نوجد 4. هل توجد فروقات ذات دلالة إحصائية عند مستوى الدلالة (1<0.05) في اتجاهات أولياء الأمور ومعلمي الصفوف الثلاث الأولى نحو استخدام

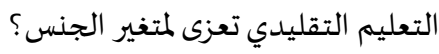

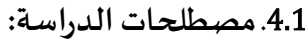
التعليم التقليدي: هو ذلك الأسلوب المعتمد على الوسائل التعليمية التقليدية القديمة التي تعتمد بشكل أساسي على تلقين المنهاج والمحتوى للطلاب وكذلك استخدام الوسائل التعليمة القديمة مثل الكتاب المدرسي، السبورة، الأقلام حيث يقتصر دور المعلم على عرض ما يملئ يملك من معلومات ومعرفة بصرف النظر عن المستوى العمري أو العقلي أو الكفاءة وهذا النوع من التعليم يرتكز على ثلاث ركائز أساسية المعلم و المتعلم والمعلومة. (سامي، إيمان، 2019) هالتعليم عن بعد: هو ذلك الأسلوب المعتمد عليه في الوسائل التعليمة الحديثة وغير التقليدية التي تعتمد بشكل أساسي على استخدام

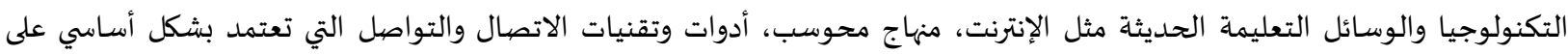

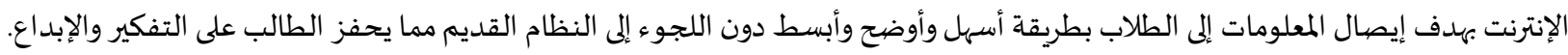

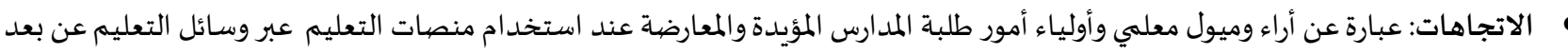

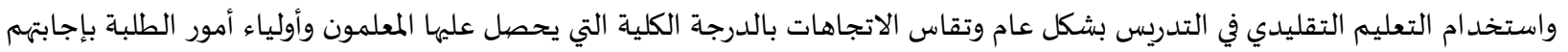

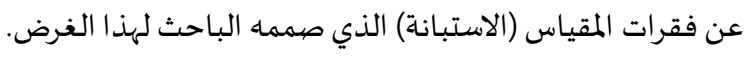

2.

مقدمة: مما لا شك فياء أن للتعليم أهمية كبيرة بالنسبة للفرد والمجتمع فهو الحجر الأساسي للتقدم، وضمان مستقبل متميز ولذلك تسعى كافة الدول إلى الاهتمام الشديد بالعملية التعليمية، وعناصرها والتي تشتمل على الطالب، المحتوى التعليمي، الطريقة، المعلم والبيئة التعليمية. (هاجر، 2019) وبسبب ما يعانيه العالم والأردن خصهوصاً جراء جائحة كورونا فقد اقتضت الحاجة إلى إغلاق المدارس والتحول التحل من التعليم التقليدي إلى التعليم

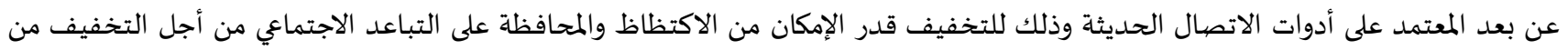
انتشار جائحة كورونا. 


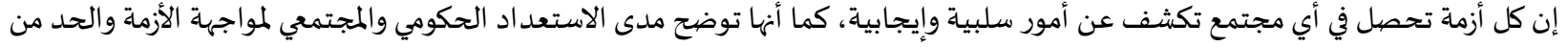

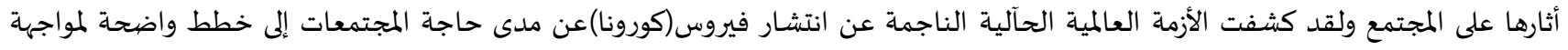

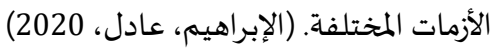

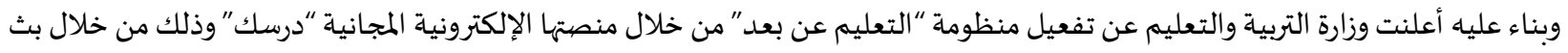
المواد التعليمية تلفزيونياً كما بادرت العديد من المدارس الخاصة على تفعيل هذه الإستراتيجية وتوفير المحتوى التعليمي إلكترونياً للطلاب أيضاً.

1.2. الفرق بين التعليم عن بعد و التعليم التقليدي: يرى الباحث أن الدراسـات أظهرت العديد من الفروق بين التعليم التيم التقليم التيدي والتعلم عن بعد، حيث يوضح الجدول التالي هذه الفروق:

\begin{tabular}{|c|c|c|}
\hline التعليم التقليدي & 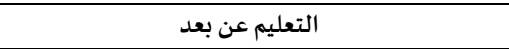 & 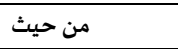 \\
\hline الأحيان & بواسطة صفحات الويب وأدوات التكنولوجيا المختلفة & أسلوب التعليم \\
\hline يسمح فقط بين المعلم والمتعلم ولا يكون بين المتعلم و الكتاب & و يقوم على مدى التفاعلية بين المتعلم والوسائط المتعددة & مدى التفاعلية التية \\
\hline التعديل - مكلفة جدا جدألكا بحأل جمع جميع الكتب وإتلافها من أجل & سهلة - غير مكلفة - تكون بعد النشر أيضا & 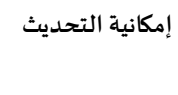 \\
\hline 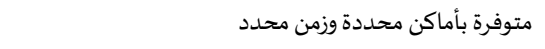 & 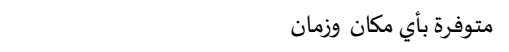 & التو افر/ الإتاحة الت \\
\hline تبسيط وإيصال المعلومة المعلم فهو الناقل والملقن وله الدور الأساسي في & المثتورة والمتعلم بصورة المعلم من حيث الإرشاد والنصيح وتقدبديم استخدام الأدوات & الاعتمادية \\
\hline غير مرن - محدد بمكان وزمان & 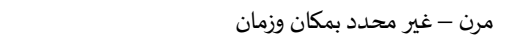 & نظام التعليم \\
\hline لا يتطلب إلى تكلفة مآلية كبيرة & ومعدات إلكترونية ملية كبيرة لأنَّه يحتاج إلى بنية تحتية وأجهزة & الكلفة المالية \\
\hline كتاب مطبوع به نصوص كتابية، و بعض الصور & 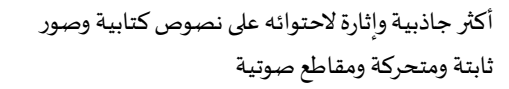 & 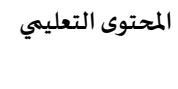 \\
\hline 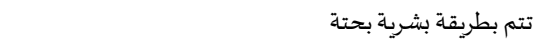 & تتم إلكترونيآ ت & المتابعة و التقييم \\
\hline سهله بسبب المراقبة المباشرة من المعلم والحد من الغش & صعبة بسبب الخوف من الممارسات الخاطئة كالغش & المصداقية \\
\hline
\end{tabular}

2.2. إيجابيات وسلبيات التعليم عن بعد و التعليم التقليدي: • • ب إيجابيات و سلبيات التعليم التقليدي:

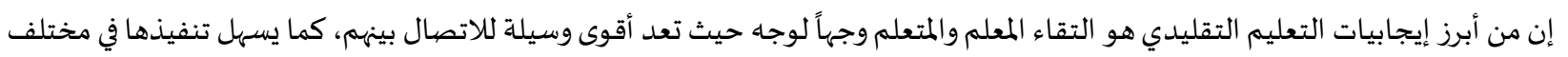
البيئات التعليمية، وتخدم شريحة كبيرة من المجتمع، وأكثر ملائمة لبعض إنبات المواد العلمية والأدبية، وتمتاز أيضاً بالتكلفة المآلية المتدنية. (سامي، إيمان،

ومن سلبيات التعليم التقليدي إغفال دور المعلم وتحويله من مشرف إلى ملقن مما يعكس آلية إيصال المعلومة للطالب واقتصارها على أسلوب

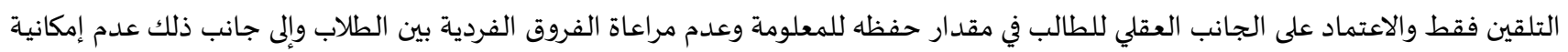
تحديث المحتوى التعليمي باستمرار للكلفة المالية العالية المترتبة على ذلك والتقليل من فرص التهاني التعليم الجيد بسبب كثافة أعداد الطلاب دابل داخل الصفوف والقاعات.

إيجابيات و سلبيات التعليم عن بعد:

إن من أبرز إيجابيات التعليم عن بعد حماية حق الطالب في التعلم وضمانيمان استمرار العملية التعليمية في كل الظروف والأحوال، وتعزيز مبدأ

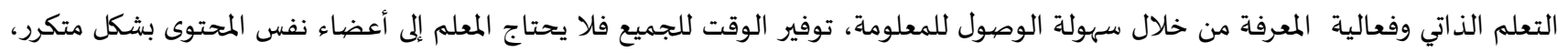

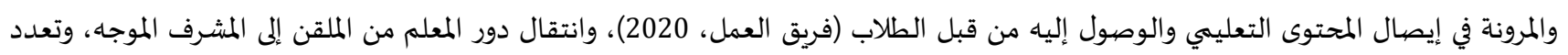
مصادر المعرفة وعدم اقتصارها على الكتاب فقط، وسهولة التواصل مع المعلم في أي وقت وطرح الأسئلة التي يريد أجوبة عنها، كما أنه يساعد على المعلى توسيع نطاق التعليم والمساهمة في التقويم الفوري والتعرف على النتائج وتصحيح الأخطاء. (سامي، إيمان، 2019)

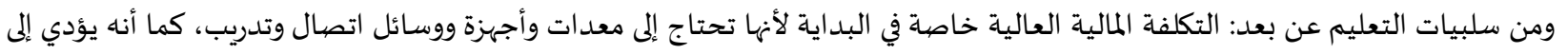

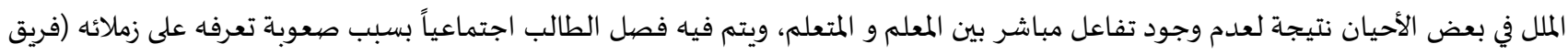

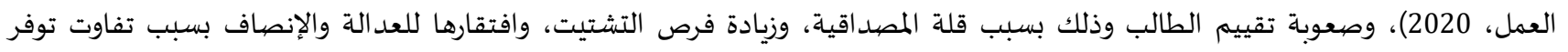


التكنولوجيا اللازمة والوقت والتحفيز للطلاب والمستوى التعليمي للوالدين الداعم للمشاركة عن بعد، وعدم مقدرة أولياء الأمور على المشـاركة الفاعلة في تعليم أبنائهم خصوصاً الطلاب في مرحلة الصفوف الثلاث الأولى حيث يحتاج مهاره عالية وأسلوب في إيصال المعلومة. (سامي، إيمان، 2019)

3.2. الدراسات السـابقة:

بعد الاطلاع على العديد من الدراسات السابقة والقريبة من موضوع الدراسة والتي تم الاطالع عليها للاستفادة منها ومقارنتها بالدراساة الحالية حيث لاحظ الباحث ندرة في الدراسات التي تبحث التعليم عن بعد خصوصياً في البيئة الأردنية والعربية حيث تم تطبيق الدراسـة عن بعد في عام 2020 وأصبح إلزامياً بسبب جائحة كورونا. قامت ألفت الأشي (2021) بإجراء دراسة حول الممارسات التربوية للوالدين في التعليم عن بعد للمرحلة الابتدائية وعلاقتها بكفاءة إدارة الوقت والجهد، وقد اعتمد البحث على المنهج الوصفي التحليلي حيث تكونت عينة الدراسـة من (500) أب و أم من أسر سعودية ولديهم طفل أو طفلة

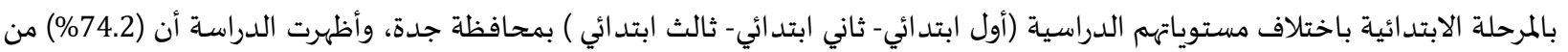

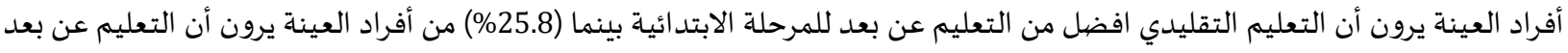

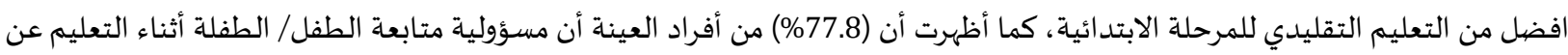

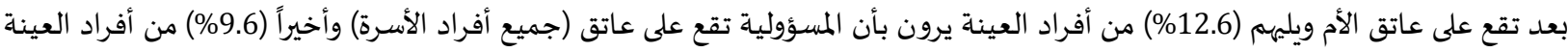

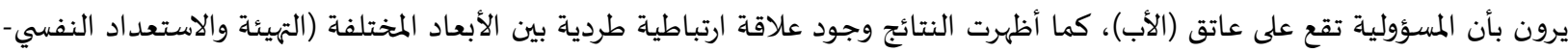

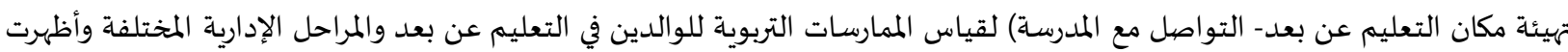

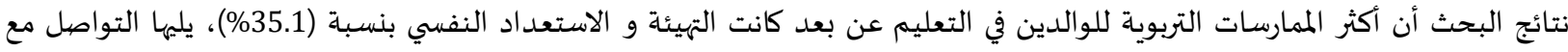

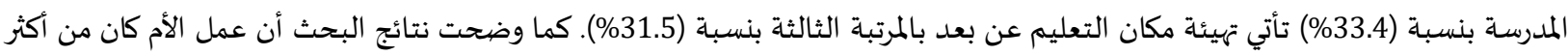

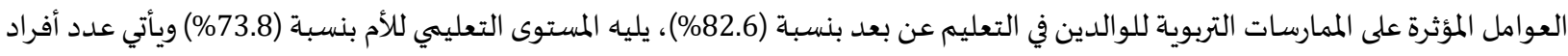

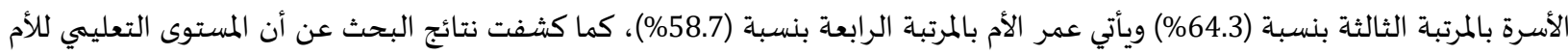
كان من أكثر العوامل المؤثرة على كفاءة إدارة الوقت والجهد بنسبة (87.7\%)، يلياه عمر الأم بنسبة (78\%) يليه المستوى التعليمي للأب بنسبة

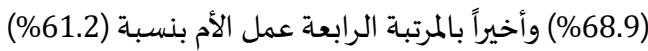
قامت وريدة أبو زيد (2021) بعمل ورقة بحثية ناقشت بها التعليم الإلكتروني ودوره في دعم العملية التعليمية وأهم المعوقات والمشكلات التي تواجها حيث قامت بعرض عرفت فيه مفهوم التعليم الإلكتروني وأهدافه و ماهية الدوافع ومسببات التوجه لسياسة التعليم الإلكتروني وأبرز

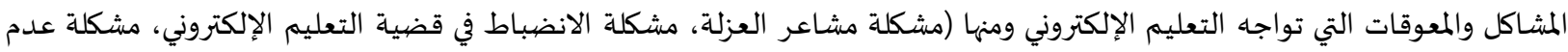

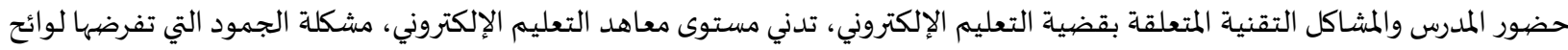
بعض الجامعات حول التعليم الإلكتروني)، كما حددت الفئات الذين يقومون باتباع سياسة و توجاه التعليم الإلكتروني وكان من أبرزها (الأفراد

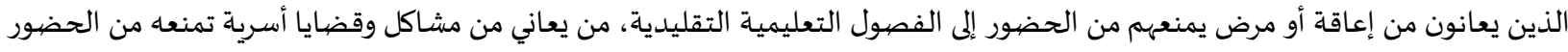

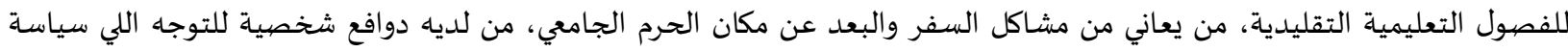
التعليم الإلكتروني، من يرغب بالعمل أثناء فترة الدراسة)، كما عرضت بعض الحلول التي من شأها صدد المعوقات التي تواجه تطبيق سياسة التعليم الإلكتروني وتتمثل ب (العمل على نشر ثقافة التعليم الإلكتروني بطريقة إبداعية إيجابية أكثر من قبل، عقد ورش و دورات تدريبية توضح

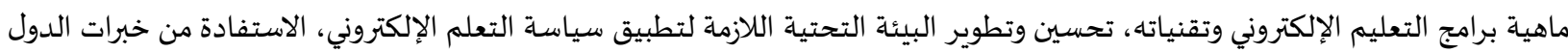

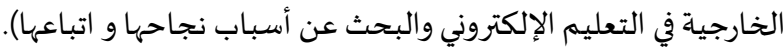

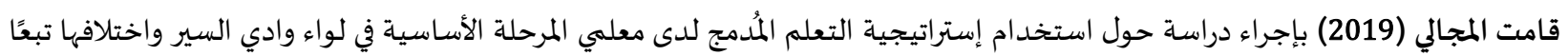

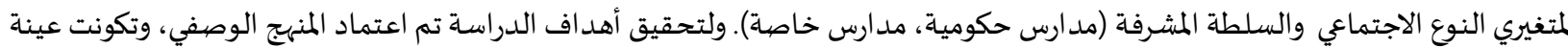

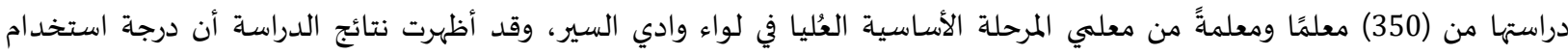

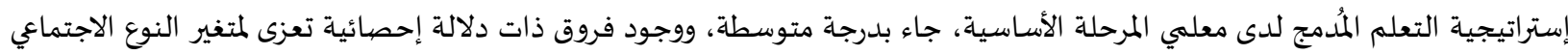

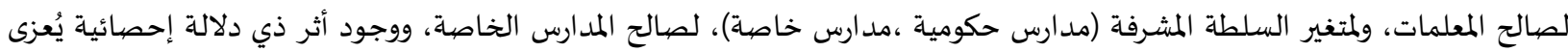

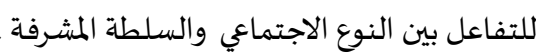

وأظهرت الحيحي، الشيماء (2018) أثر استخدام التعلم الإلكتروني في تدريس مادة اللغة الإنجليزية في تنمية الذكاءات المتعددة لدى طلاب الصف الخامس الأساسي في محافظة العاصمة/عممان، وتكونت عينة دراستها التي كانت بالطريقة القصدية التهاء لملائمة أهداف الدراسـة من (46) طالباً من طلاب الصف الخامس الأسـاسي في محافظة العاصممة، ووزعت عينة الدراسة بالطريقة العشوائية إلى مجموعاة تجريبية مكونة من (25) طالباً، وضابطة مكونة من (21) طالباً، استخدمت الباحثة وطورت مقياس تقدير الذكاءات النمائية المتعددة للأطفال (ميداس) وأظهرت النتائج 


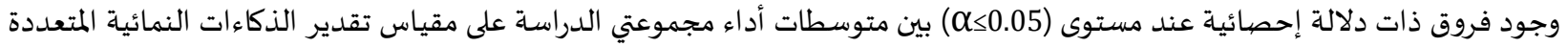
لصالح المجموعة التجريبية، التي درست باستخدام التعلم الإلكتروني. ونجد أن مارتينسين (Martinsen, 2017) في دراسته هدف إلى تعرف إمكانات ومعوقات استخدام التعلم المدمج، لمعرفة تصهورات كل من المعلم والمتعلم للتعلم المدمج في صفين من صفوف العلوم الثانوية في أستراليا. وتم استخدام إستراتيجية المنهج المختلط في جمع وتحليل البيانات الكمية

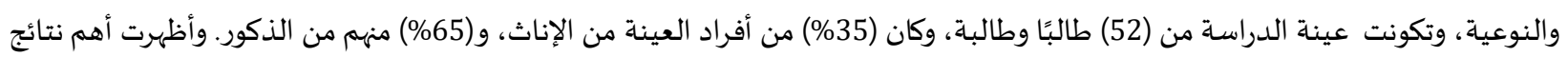

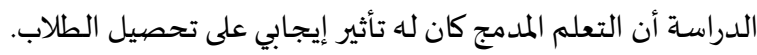
بينما سيلان وكاسيتشي (Ceylan \& Kesici, 2017) قد أجريا دراسة بهدف التحقق من أثر التعلم المُدمج على التحصيل الأكاديمي، واستخدموا

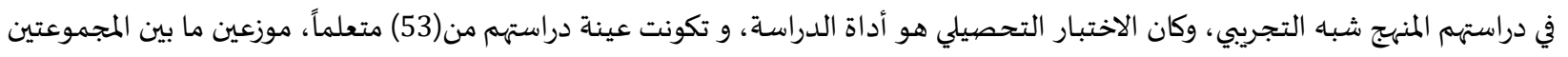

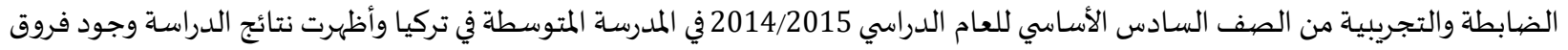
ذات دلالة إحصائية في التحصيل الأكاديمي للمتعلمين لصالح المجموعة التجريبية التي درست من خلال بيئة التعلم المدمج. في حين أن الهدهود والحطامي (AL-Hadhoud \& AL-Hattami , 2017) قاما بدراسة هدفت إلى تعرف واقع تنفيذ التعليم المتمازج في مديرية تربية عمان الخامسة والصعوبات التي تعوق عملية تنفيذه في الميدان، وتم استخدام المنهج المستي الوصفي، وتكون مجتمع الدراسة من جميع

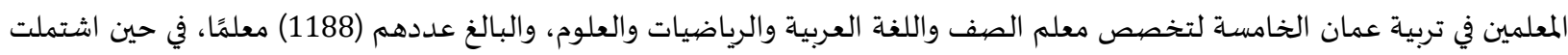

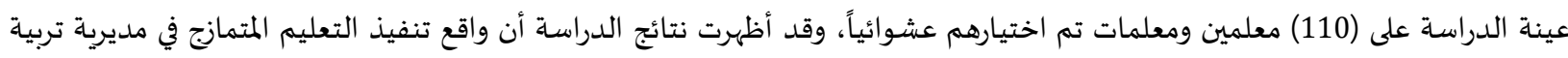

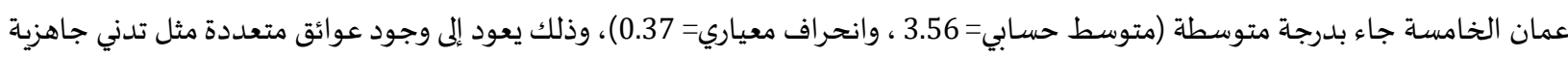

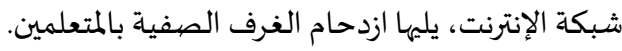

بينما مرشود في دراسته التي أجراها عام (2016) هدف إلى تعرف صعوبات تطبيق التعلم المدمج في مدارس وكالة الغوث الدولية في شمال

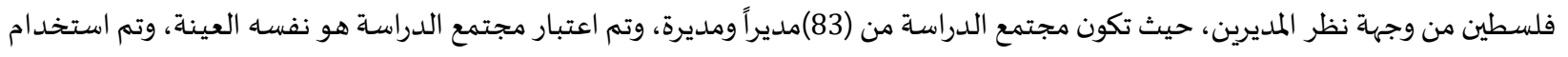

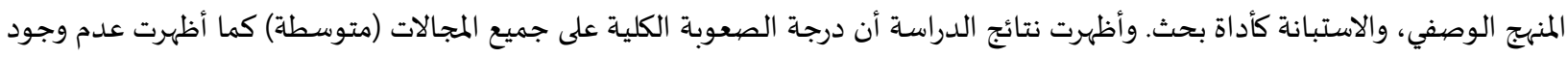

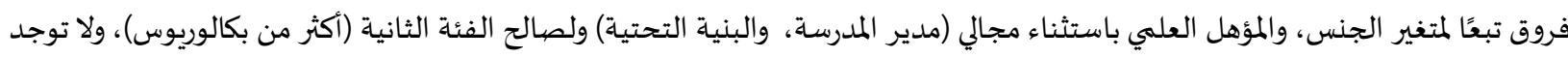
فروق تبعًا لمتغير سنوات الخبرة الإدارية باستثناء مجالي(مدير المدرسة، والبنية التحتية) ولصالح الفئة الثانية (من 5-10 سنواتية). وكذلك نجد أن الشكعة (2016) استقصت في دراستها أثر إستراتيجيتي التعلم المدمج والتعلم المعكوس في تحصيل طلبة الصف السابع في مادة

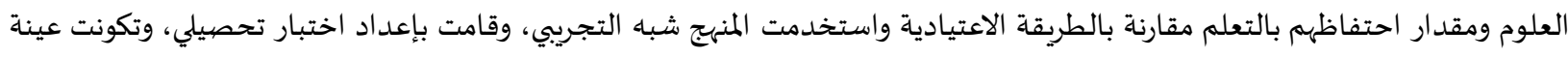

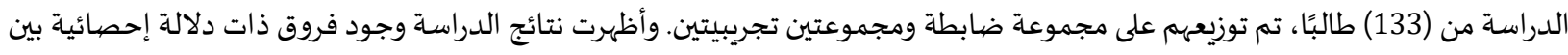
متوسطات درجات الطلاب في الاختبار التحصيلي لصالح المجموعتين التجريبيتين ولصالح المجموعائ التي تعلمت بإستراتيجية التعلم المدمعج مقارنة بالمجموعة التي تعلمت بإستراتيجية التعلم المعكوس. كما أجرى النحال وعقل (2016) دراسة هدفت إلى قياس مدى تأثير توظيف إستراتيجية المشاريع الإلكترونية في تنمية مهارة تصميم المواقع في

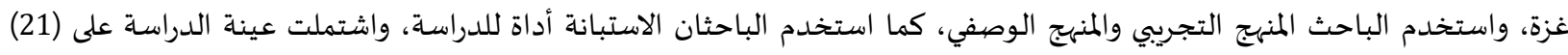

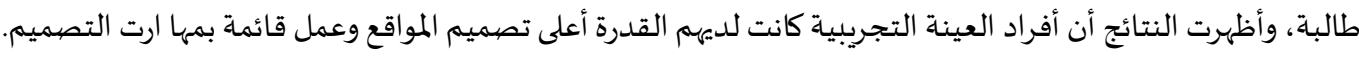
أما الفهيد (2015) فقد أجرى دراسة هدفت التعرف إلى واقع استخدام التعليم المدمج في تدريس العلوم الطبيعية في المرحلة الثانوية من وجهات

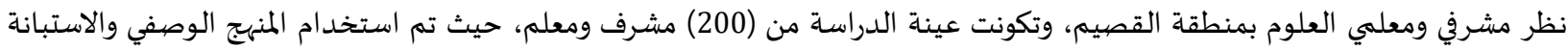
كأداة بحث، وأظهرت النتائج ارتفاع موافقة أفراد العينة في محور أهمية استخدام التعلم المدمجة، بينما جاءت مونة موافقة أفراد العينة بصيورة متوسطة في محور درجة استخدامها.

وكذلك هدفت دراسـة كر اكرفت (Cracraft, 2015) إلى تعرف تأثير التعلم المدمج في زيادة النسب المئوية لدرجات تقييم المتعلمين وتعرّف أثر

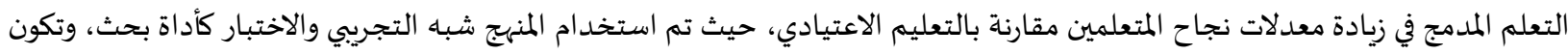
مجتمع الدراسة من طلبة الصف الخامس في مدرسة ابتدائية في مدينة ميدويست في الولايات المتحدة الأمريكية، حيث تكونت عينات المئة الدراسة

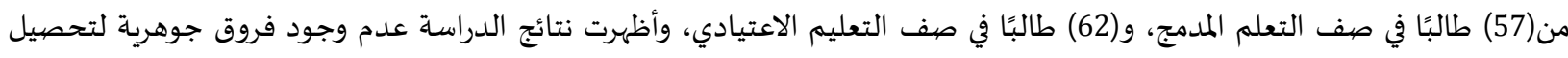
المتعلمين في الصف المدمج مقارنة بالصف التقليدي. 
3. منهجية و إجراءات الدراسـة:

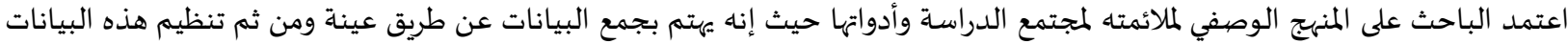

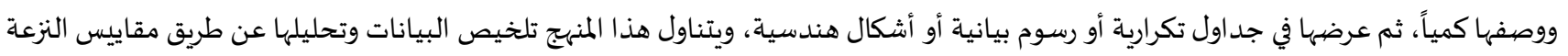

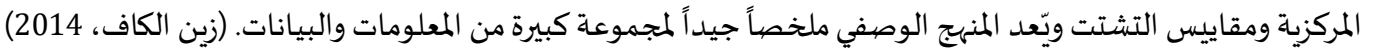

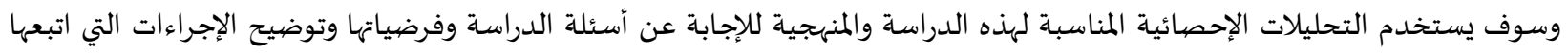

الباحث في تنفيذ الدراسة الحالية.

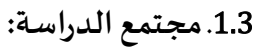

تكون مجتمع الدراسة من معلمي ومعلمات الصفوف الثلاثة الأولى في مدارس مديريات التربية والتعليم في العاصمية عمان واندان ومن أولياء أمور الطلبة

على اختلاف طبقاتهم الاجتماعية ومستواهم التعليمي في مدارس مديريات التربية والتعليم في العاصمة عمانيان.

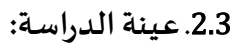

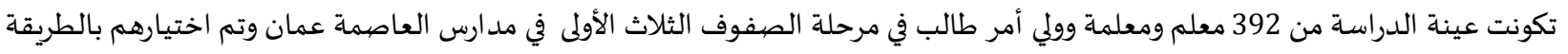

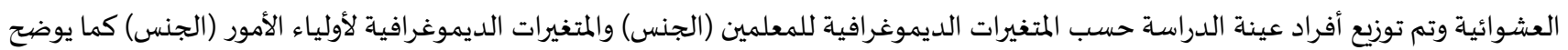

الجدولان التاليان (2)،(3)

\begin{tabular}{|c|c|c|}
\hline النسبة المئوية & أفراد العينة & الفئة \\
\hline$\% 40.1$ & 157 & المعلمين \\
\hline$\% 59.9$ & 235 & أولياء الأمور \\
\hline
\end{tabular}

\begin{tabular}{|c|c|c|c|}
\hline النسبة المئوية & العدد & الفئات & المتغير \\
\hline$\% 41.4$ & 65 & ذكر & \\
\hline$\% 58.6$ & 92 & أنثى & الجنس \\
\hline$\% 100$ & 157 & المجموع & \\
\hline
\end{tabular}

يوضح الجدول (3) توزع أفراد عينة الدراسـة حسب متغيراتها الديموغرافية، حيث كانت نسبة الذكور(41.4\%) أما نسبة الإناث فقد كانت (58.6

\begin{tabular}{|c|c|c|c|}
\hline النسبة المئوية & العدد & الفئات & المتغير \\
\hline$\% 39.6$ & 93 & ذكر & \\
\hline$\% 60.4$ & 142 & أنثى & الجنس \\
\hline$\% 100$ & 235 & المجموع & \\
\hline
\end{tabular}

يبين الجدول (4) توزع أفراد عينة الدراسة من أولياء الأمور حسب متغيراتها الديموغرافية، حيث كانت نسبة الذكور(39.6 \%)، أما نسبة الإناث

فكانت (60.4 \%).

3.3 أداة الدراسـة:

للإجابة عن أسئلة الدراسة واختبار فرضياتها قام الباحث ببناء استبانتين أولهما للمعلمين والثانية لأولياء الأمور وذلك لمعرفة اتجاهات أولياء

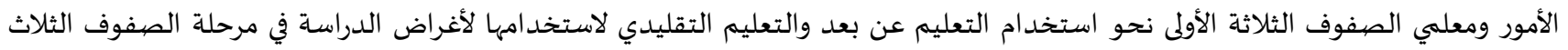

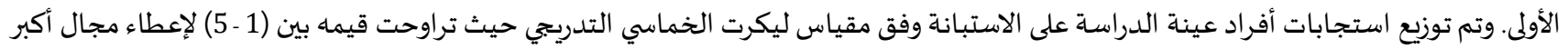

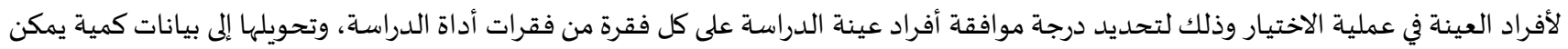

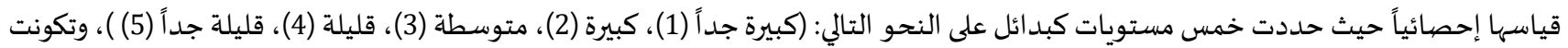
استبانة المعلمين/المعلمات من (34) أما بالنسبة لاستبانة أولياء الأمور فقد تكونت أيضا من (23) والجدول (5) يوضح ذلك. 
جدول (5): توزيع فقرات الاستبانة على مجالاتها

\begin{tabular}{|c|c|c|}
\hline استبانة موجهه إلى & عدد الفقرات & مجالات الاستبانة \\
\hline المعلمين & 1 & المعلومات الديموغر افية \\
\hline أولياء الأمور & 1 & \\
\hline المعلمين & 6 & الاحتياجات التكنولوجية و التدريبية \\
\hline أولياء الأمور & 6 & \\
\hline المعلمين & 15 & ما يتعلق بالتعليم عن بعد \\
\hline أولياء الأمور & 6 & \\
\hline المعلمين & 8 & ما يتعلق بالتعليم التقليدي \\
\hline أولياء الأمور & 5 & \\
\hline
\end{tabular}

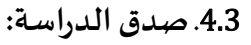

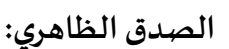

تم التحقق من الاستبانة بعرضها على مجموعة من المحكمين من ذوي الاختصاص في مجال التربية والتكنولوجيا وعددهم (7) محكمين لأبداء

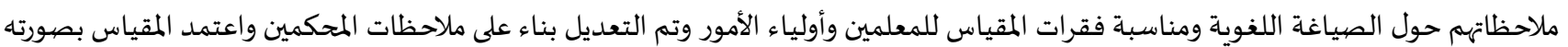

لحساب الصددق البنائي تم تطبيق الاستبانة على عينة استطلاعية بلغت 10 معلمين و 10 من أولياء الأمور وتم حساب معامل ارتباط بيرسون ويرمز له (R) والذي يظهر قدرة كل فقرة من فقرات الدراسة ومدى ارتباطها بالبعد الذي تنتمي آلية والجدول (6) و الجدول (7) يوضح ذلك.

\begin{tabular}{|c|c|c|c|c|c|}
\hline معامل الارتباط & الفقرة & معامل الارتباط & الفقرة & معامل الارتباط & الفقرة \\
\hline $.716^{* *}$ & س 21 & $.703^{* *}$ & س 11 & $.799^{* *}$ & س 1 \\
\hline $.789^{* *}$ & س 22 & $.712^{* *}$ & س 12 & $.792^{* *}$ & س 2 \\
\hline $.823^{* *}$ & س 23 & $.777^{* *}$ & س 13 & $.777^{* *}$ & س 3 \\
\hline $.818^{* *}$ & س 24 & $.779 * *$ & س 14 & $.789^{* *}$ & س 4 \\
\hline $.797 * *$ & س 25 & $.717^{* *}$ & س 15 & $.767^{* *}$ & س 5 \\
\hline $.804^{* *}$ & س 26 & $.737^{* *}$ & س 16 & $.840^{* *}$ & س 6 \\
\hline $.824^{* *}$ & س 27 & $.750^{* *}$ & س 17 & $.700^{* *}$ & س 7 \\
\hline $.793^{* *}$ & س 28 & $.790^{* *}$ & س 18 & $.760^{* *}$ & س 8 \\
\hline \multirow[t]{2}{*}{$.864^{* *}$} & س 29 & $.692^{* *}$ & س 19 & $.679 * *$ & س 9 \\
\hline & & $.673^{* *}$ & س 20 & $.704^{* *}$ & س 10 \\
\hline
\end{tabular}

يوضح الجدول (6) قيم الفقرات و معامل الارتباط الكلي لها في استبانة المعلمين حيث إن الفقرات من س 1 إلى س 6 تمثل محور الاتجاه نحو

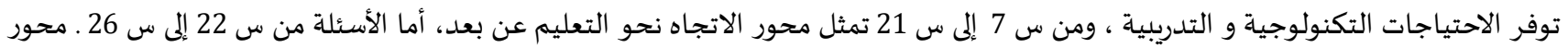
الاتجاه نحو التعليم التقليدي. وكانت أدنى قيمة لمعامل ارتباط (*0.673) وكانت للفقرة س 20 والتي تنتمي لمحور الاتجاه نحو التعليم عن بعد، وجميعها دالة إحصيائياً عند

مستوى 0.01 وعليه تعتبر الفقرات صيادقة بنائياً.

جدول (7): قيمة معامل الارتباط بيرسون بين فقرات استبانة أولياء الأمور

\begin{tabular}{|c|c|c|c|}
\hline معامل الارتباط & الفقرة & معامل الارتباط & الفقرة \\
\hline $0.796^{* *}$ & س 10 & $0.886^{* *}$ & س 1 \\
\hline $0.765 * *$ & س 11 & $0.860^{* *}$ & س 2 \\
\hline $0.815^{* *}$ & س 12 & $0.881^{* *}$ & س 3 \\
\hline $0.855^{* *}$ & س 13 & $0.906^{* *}$ & س 4 \\
\hline $0.898^{* *}$ & س 14 & $0.916^{* *}$ & س 5 \\
\hline $0.933^{* *}$ & س 15 & $0.920^{* *}$ & س 6 \\
\hline $0.812^{* *}$ & س 16 & $0.702^{* *}$ & س 7 \\
\hline \multirow[t]{2}{*}{$0.909 * *$} & س 17 & $0.871^{* *}$ & س 8 \\
\hline & & $0.895^{* *}$ & س 9 \\
\hline
\end{tabular}


يوضح الجدول (7) قيم الفقرات ومعامل الارتباط الكلي لها في استبانة أولياء الأمور حيث إن الفقرات من س 1 إلى س 6 تمثل محور الاتجاه نحو الاحتياجات التكنولوجية والتدريبية، ومن س 7 إلى س 12 تمثل محور الاتجاه نحو التعليم عن بعد، بينما يتمثل محور الاتجاه نحو التعليم التقليدي ب س 13 إلى س 17. وأقل قيمة لمعامل ارتباط (*2*02) وكانت للفقرة س 7 والتي تنتمي لمحور الاتجاه نحو التعليم عن بعد وجميعها دالة إحصائياً عند 0.01 وعليه تعتبر الفقرات صادقة بنائياً.

5.3 ثبات الدراسـة:

للتحقق من ثبات الاستبانة تم تطبيقها على عينة استطلاعية مكونة من (10) من المعلمين و(10) من أولياء الأمور خارج عينة الدراسـة حيث بلغ

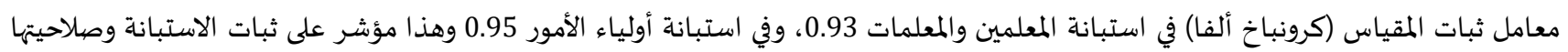
للتطبيق.

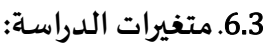

تم تحديد متغير الدراسة الحآلية على النحو التالي: متعرات المتغير المستقل: الجنس. المتغير التابع : اتجاه العينة نحو جدوى التعلم التقليدي والتعلم عن بعد للصفوف الثلاثة الأولى من المرحلة الابتدائية.

7.3. المعالجـة الإحصيائية:

اعتمدت الدراسة على برنامج الحاسوب الإحصائي (SPSS) لإجراء المعالجة الإحصائية المناسبة: • المتوسطات الحسابية والانحرافات المعيارية والرتب للتعرف على درجة استجابة أفراد عينة الدراسة على فقرات الاستبانة. اختبار (t-test) للتعرف على دلالة الفروق في متغير (الجنس) نحو جدوى التعليم عن بعد. اختبار (t-test) للتعرف على دلالة الفروق في متغير (الجنس) نحو التعليم التقليدي. معامل ارتباط بيرسون للتحقق من صدق الاستبانتين. معامل كرونباخ ألفا للتحقق من ثبات الاستبانتين.

لتحديد درجات موافقة أفراد عينة الدراسة على كل فقرة من فقرات الدراسة تم استخد ام المعادلة التالية: (Subedi,2016)

\section{طول الفئة = الحد الأعلى - الحد الأدنى = 3 عدد المستويات}

وعليه تصبح درجة الموافقة الأولى (1 - 2.33) وتمثل المستوى المنخفض ودرجة الموافقة الثانية (2.34 - 3.66) تمثل المستوى المتوسط، ودرجة الموافقة الثالثة (3.67 - 5) المستوى مرتفع دوجة

8.3. إجراءات الدراسـة:

الاطلاع على المراجع والدراسات والأبحاث السابقة والمقالات الموثقة وتوصيات المؤتمرات ذات الصلة. تطوير الاستبانتين بالرجوع إلى بعض الدراسات ثم عرضها على مجموعة محكمين والخروج باستبانة نهائية وبدرجة موافقة كبيرة. إعد اد الاستبانتين إلكترونياً بالاعتماد على نماذج جوجل لسهولة إيصالها وجمع النتائج وتحليلها وذلك بسبب جائحة كورونا وبروتوكولات التباعد الاجتماعي. نشر الاستبانة عبر تطبيق (WhatsApp) ومواقع التواصل الاجتماعي ( Facebook) والتواصل هاتفيا مع مجموعة من معلمي الصفوف الثلاث الأولى في العاصيمة عمان وأولياء أمور الطلبة. تحليل البيانات إحصائياً حيث تم جمع البيانات وتزويد المحلل الإحصائي باستجابات الاستبانتين إلكترونياً ومن ثم تفريغها في جداول وتحليلها إحصائياً. عرض النتائج ومناقشتها. تقديم التوصيات والمقترحة حسب ما يتم التوصل إلياه من نتائج. 


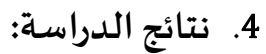

يتناول هذا الجزء عرض لنتائج الدراسة التي هدفت إلى معرفة اتجاهات أولياء الأمور ومعلمي الصفوف الثلاثة الأولى نحو استخدام التعليم عن

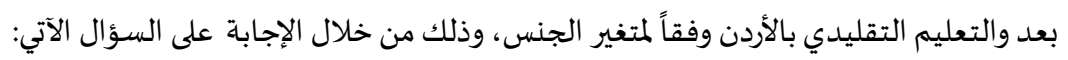

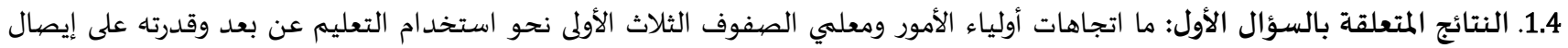

المعلومة للطالب؟

من وجهه نظر المعلمين: للإجابة على هذا السؤال تم احتساب المتوسطات الحسابية والانحرافات المعيارية والرتب ودرجة الموافقة لمجالات الاستبانة وفق هذا الجانب والجدول (8) التالي يوضح ذلك: جدول (8): المتوسطات الحسابية والانحر افات المعيارية والرتب ودرجة المو افقة لمجالات الاستبانة من وجهة نظر المعلمين المبند

\begin{tabular}{|c|c|c|c|c|c|}
\hline 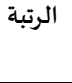 & المو افقة & المعياري & الحسابي & 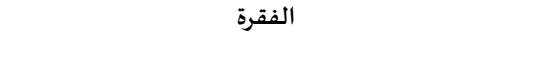 & 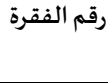 \\
\hline 14 & متوسطة & 1.128 & 2.83 & أتفهم إستراتيجيات التعليم عن بعد & 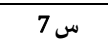 \\
\hline 13 & متوسطة & 1.044 & 2.87 & أقدر على تفعيل إستراتيجيات التعليم عن بعد & 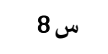 \\
\hline 15 & متوسطة & 1.057 & 2.74 & تدن بعد على آلية الدخول واستخدام المواقع الخاصة بالتعليم & 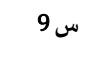 \\
\hline 12 & متوسطة & 1.051 & 2.87 & اللعدرعلى اختيار النوع المناسب من الوسائط المتعددة & 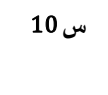 \\
\hline 10 & متوسطة & 1.070 & 2.94 & 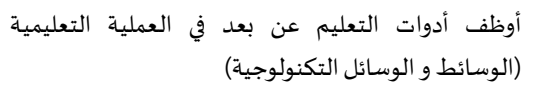 & 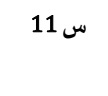 \\
\hline 8 & متوسطة & 1.145 & 3.06 & تحقيق الأهداف التعليمية للتعليم الإككتونية المناسبة لمساعدة الطلبة في & س \\
\hline 4 & 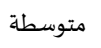 & 1.099 & 3.26 & يساعد التعليم عن بعد في إيصال المعلومة للطالب & 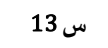 \\
\hline 11 & متوسطة & 1.168 & 2.88 & عن بعديع إعداد أوراق عمل للطلاب عند استخدام التعليم & 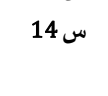 \\
\hline 3 & متوسطة & 1.120 & 3.28 & يمكنني قياس المستوى الأكاديمي للطلبة في التعليم عن بعد & 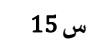 \\
\hline 6 & متوسطة & 1.222 & 3.14 & 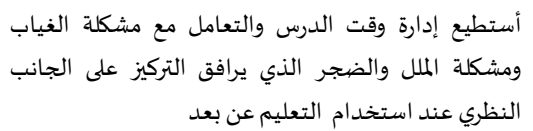 & 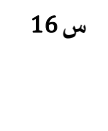 \\
\hline 2 & متوسطة & 1.110 & 3.29 & تسههم إستراتيجيات التعليم عن بعد في زيادة مقدرة الطلبة & س 17 \\
\hline 9 & متوسطة & 1.139 & 3.06 & 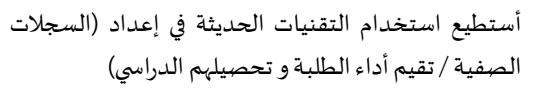 & ( \\
\hline 1 & متوسطة & 1.241 & 3.57 & للطلبة استخدام التعليم عن بعد يسهم رفع المستوى الاكاديمي & س \\
\hline 7 & متوسطة & 1.289 & 3.11 & 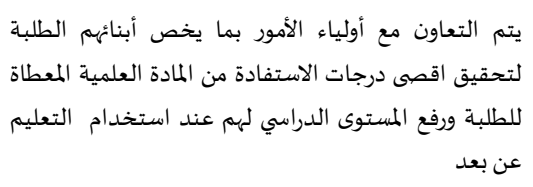 & 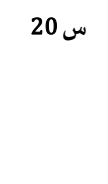 \\
\hline 5 & متوسطة & 1.236 & 3.17 & يتم تقديم تغذية راجعة بشكل مباشر عند استخدام & 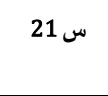 \\
\hline & متوسطة & 0.828 & 3.07 & المؤشر العام & \\
\hline
\end{tabular}

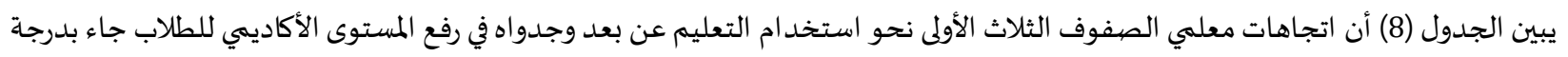

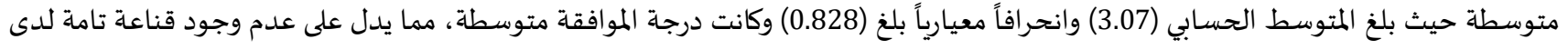

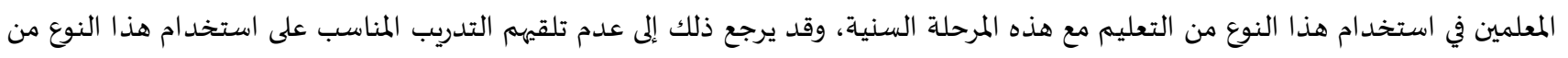

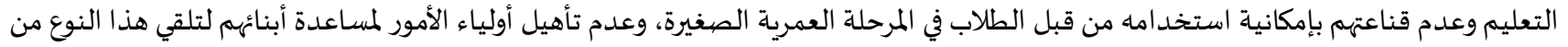

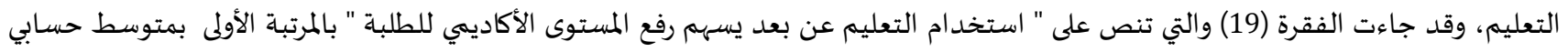

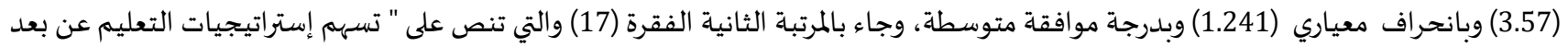

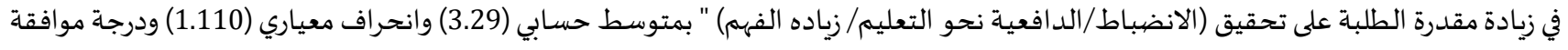

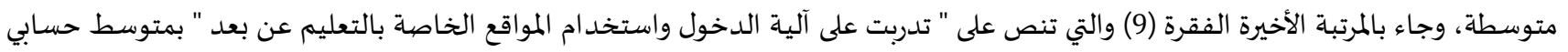


(2.74) وبانحراف معياري (1.057) وبدرجة موافقة متوسطة، وهذا الترتيب يؤكد على أن المعلمين لديهم اتجاه إيجابي نحو التعليم عند بعد لما يرون فيه من إمكانيات ولكنهم لم يتلقوا تدريباً مناسباً على استخد امداريه. • • من وجهة نظر أولياء الأمور: إمداء لمعرفة اتجاهات أولياء الأمور نحو جدوى التعليم عن بعد تم احتساب المتوسطات الحسابية والانحرافات المعيارية والرتب ودرجة الموافقة لمجالات الاستبانة وفق هذا الجانب و الجدول (9) التالي يوضيح ذلك.

\begin{tabular}{|c|c|c|c|c|c|}
\hline 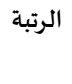 & المو افقة & المعياري & الحسابي & 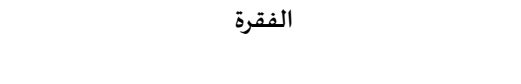 & 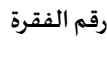 \\
\hline 6 & متوسطة & 1.174 & 2.85 & تدربت على الدخول واستخدام المواقع الخاصة بالتعليم & س \\
\hline 3 & متوسطة & 1.092 & 3.63 & يسهم التعليم عن بعد في وصول المعلومة للطالب & 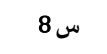 \\
\hline 4 & متوسطة & 1.165 & 3.57 & للطلبة التعليم عن بعد في تحسين المستوى الأكاديمي & س 9 \\
\hline 2 & 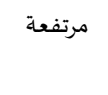 & 1.045 & 3.93 & 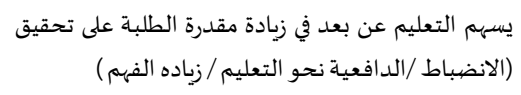 & 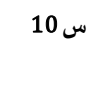 \\
\hline 5 & متوسطة & 1.143 & 3.35 & 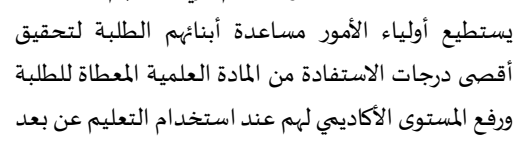 & س 11 \\
\hline 1 & 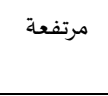 & 1.114 & 4.08 & يرضيني & 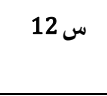 \\
\hline
\end{tabular}

يبين الجدول (9) أن اتجاهات أولياء الأمور نحو استخدام التعليم عن بعد جاءت بدرجة متوسطة حيث بلغ المتوسط الحسابي لهذا الجزء (3.57)

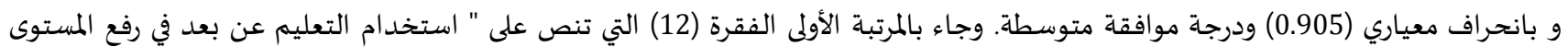
الأكاديمي للطلبة يرضيني " بمتوسط حسابي (4.08) وانحراف معياري (1.114) وبدرجة موافقة مرتفعة مما يدل على وجود اتجاه إيجابي لدى أولياء

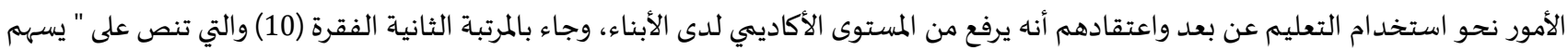
التعليم عن بعد في زيادة مقدرة الطلبة على تحقيق (الانضباط/الدافعية نحو التعليم/ زياده الفهم) " بمتوسط حسابي (3.93) وانحراف معياري

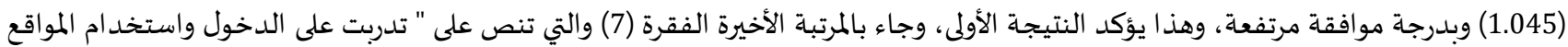

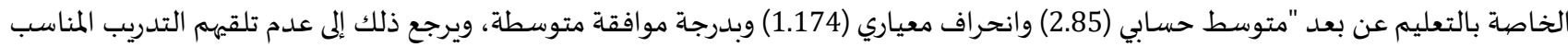

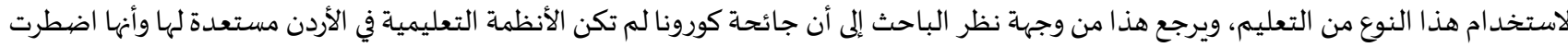

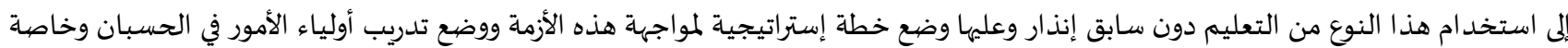
أولياء أمور طلاب الصفوف الثيلاث الأولى.

2.4. النتائج المتعلقة بالسؤال الثاني: ما اتجاهات أولياء الأمور ومعلمي الصفوف الثلاث الأولى نحو استخدام التعليم التقليدي وقدرته على إيصال

المعلومة للطالب؟ من وجهه نظر المعلمين: للإجابة عن هذا السؤال تم احتسـاب المتوسطات الحسابية والانحرافات المعيارية والرتب ودرجة الموافقة لمجالات الاستبانة وفق هذا الجانب والجدول (10) التالي يوضح ذلك: 


\begin{tabular}{|c|c|c|c|c|c|}
\hline الرتبة & المو افقة & 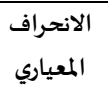 & الحسبابي & الفقرة & رقم الفقرة \\
\hline 7 & منخفضية & 1.032 & 2.21 & التقليدي المعلومة للطالب بسهولة عند استخدام آلية التعليم & س 22 \\
\hline 5 & منخفضة & 0.997 & 2.22 & التقلطيديع إعداد أوراق عمل للطلاب عن استخدام التعليم & س 23 \\
\hline 2 & منخفضة & 1.256 & 2.29 & آلية التعليم قياس التقليديتوى الأكاديمي للطلبة عند استخدام & س 24 \\
\hline 4 & منخفضية & 1.046 & 2.24 & 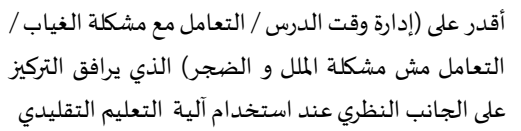 & س 25 \\
\hline 6 & منخفضة & 1.064 & 2.22 & 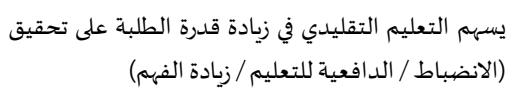 & س 26 \\
\hline 8 & منخفضة & 1.083 & 2.18 & الأكهيم استخدام التعليم التقليدي في رفع المستوى & س 27 \\
\hline 1 & منخفضة & 1.061 & 2.31 & 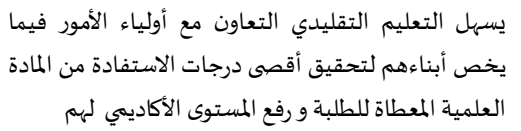 & س 28 \\
\hline 3 & منخفضية & 1.099 & 2.26 & تققدم تغذية راجعة بشكل مباشر عند استخدام التعليم & س 29 \\
\hline & منخفضية & 0.879 & 2.24 & المؤشر العام & \\
\hline
\end{tabular}

يبين الجدول (10) أن المتوسط الحسابي لهذا المحور بلغ (2.24) وبانحراف معياري (0.879) وبدرجة موافقة منخفضية. وجاء بالمرتبة الأولى الفقرة

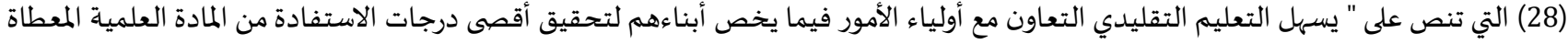

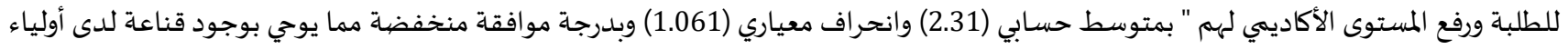

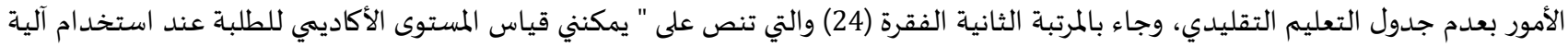

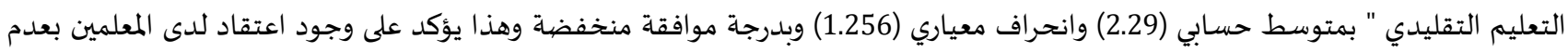

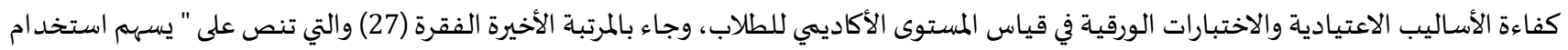

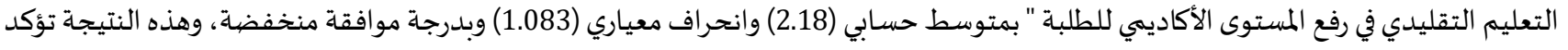

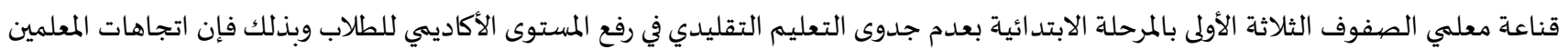

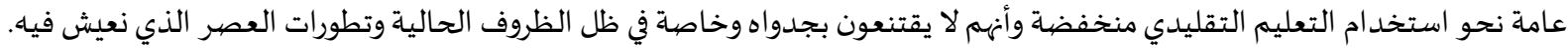

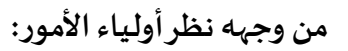
للإجابة عن هذا السؤال تم احتساب المتوسطات الحسابية والانحرافات المعيارية والرتب ودرجة الموافقة لمجالات الاستبانة وفق هذا الجانب والجدول (11) التالي يوضح ذلك. جدول (11): المتوسطات الحسابية والانحر افات المعيارية والرتب ودرجة المو افقة لمجالات الاستبانة من وجهة نظر أولياء الأمور

\begin{tabular}{|c|c|c|c|c|c|}
\hline الرتبة & المو افقة & المعياري & الحسابي & الفقرة & رقم الفقرة \\
\hline 3 & منخفضية & 1.097 & 2.17 & التقليدي المملومة للطالب بسهولة عند استخدام آلية التعليم & س 13 \\
\hline 2 & منخفضة & 1.094 & 2.23 & الاكاديمي للطلبة استخدام التعليم التقليدي في رفع المستوى & س 14 \\
\hline 5 & منخفضة & 1.117 & 2.07 & (الانضباط / الدافعية للتعليم / زيادة الفهم) فيدادة الطبلة على تحقيق & س 15 \\
\hline 1 & منخفضة & 1.096 & 2.30 & 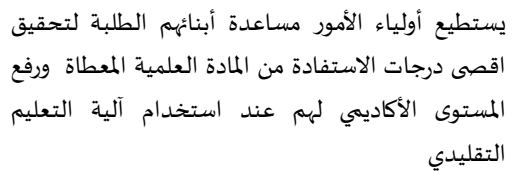 & س 16 \\
\hline 4 & منخفضة & 1.200 & 2.14 & للطلبة يرضيني التعليم التقليدي في رفع المستوى الأكاديمي & س 17 \\
\hline & منخفضية & 0.989 & 2.18 & المؤشر العام & \\
\hline
\end{tabular}


يبين الجدول (11) أن المتوسط الحسابي لهذا المحور بلغ (2.18) وبانحراف معياري (0.989) وبدرجة موافقة منخفضية. وجاء بالمرتبة الأولى الفقرة (16) التي تنص على " يستطيع أولياء الأمور مساعدة أبنائهم الطلبة لتحقيق اقصى درجات الاستفادة من المادة العلمية المعططاة ورفع المستوى الأكاديمي

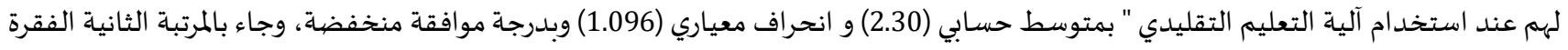

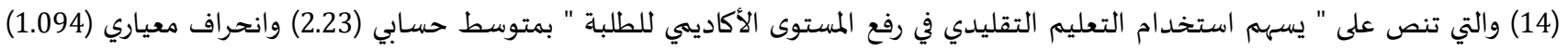

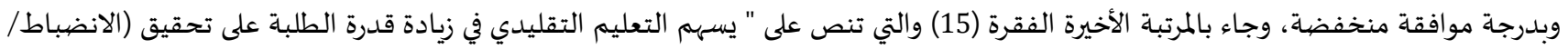

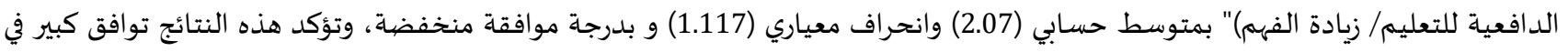
الرؤية بين المعلمين وأولياء الأمور نحو استخدام التعليم التقليدي وجدوادهاه في رفع المستوى الأكاديمي للطابلاب.

3.4. النتائج المتعلقة بالسؤال الثالث: هل توجد فروق ذات دلالة إحصائية عند مستوى الدلالة (X0.05) في اتجاهات أولياء الأمورومعلمي

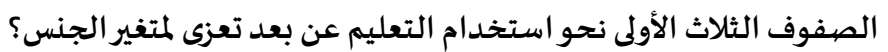

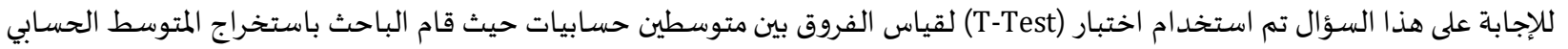

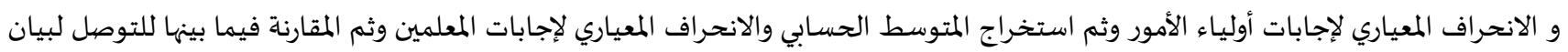
الفروق الإحصائية بين المتوسطات الحسابية والجدول (12) التالي يوضح ذلك.

\begin{tabular}{|c|c|c|c|c|c|c|}
\hline 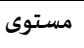 & قيمة ت & الانحراف المعياري & الوسط الحسابي & العدد & النوع ل & التصنيف \\
\hline \multicolumn{7}{|l|}{ 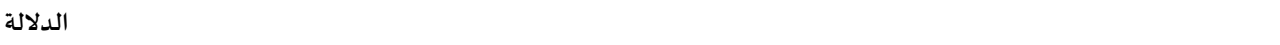 } \\
\hline \multirow[t]{2}{*}{0.336} & \multirow[b]{2}{*}{0.988} & 0.82 & 3.06 & 65 & ذكور & \multirow[t]{2}{*}{ المعلمين } \\
\hline & & 0.73 & 3.08 & 92 & إناث & \\
\hline \multirow[t]{2}{*}{0.453} & \multirow[t]{2}{*}{0.888} & 0.9 & 3.5 & 93 & ذكور & \multirow[t]{2}{*}{ أولياء الأمور } \\
\hline & & 0.87 & 3.62 & 142 & إناث & \\
\hline
\end{tabular}

يتضع من الجدول (12) عدم وجود فروق ذات دلالة إحصائية في اتجاهات المعلمين وأولياء الأمور نحو استخدام التعليم عن بعد وجدواه في رفع المستوى الأكاديمي لدى الطلاب، وأن جنس المعلمين وأولياء الأمور لا يؤثر في اتجاهات عيدات عينة الدراسة

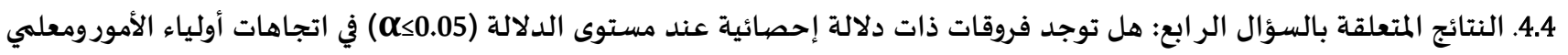

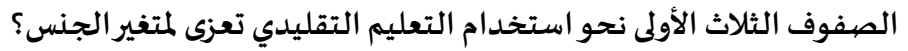

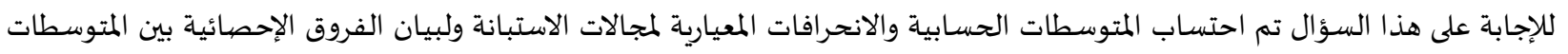

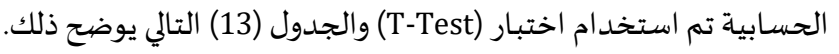

جدول (13): اختبار(T-Test) لبيان الفروق الإحصائية بين المتوسطات الحسابية

\begin{tabular}{|c|c|c|c|c|c|c|}
\hline مستول الدلالة & قيمة ت & الانحراف المعياري & الوسط الحسابي & العدد & النوع & التصنيف \\
\hline \multirow[t]{2}{*}{0.44} & 0.77 & 0.63 & 2.2 & 65 & ذكور & المعلمين \\
\hline & & 0.65 & 2.28 & 92 & إناث & \\
\hline \multirow[t]{2}{*}{0.52} & 0.75 & 0.6 & 2.19 & 93 & ذكور & أولياء الأمور \\
\hline & & 0.61 & 2.17 & 142 & إناث & \\
\hline
\end{tabular}

يتضح من الجدول (13) عدم وجود فروق ذات دلالة إحصائية في اتجاهات المعلمين وأولياء في اتجاهاتهم نحو استخدام التعليم التقليدي وجدواه

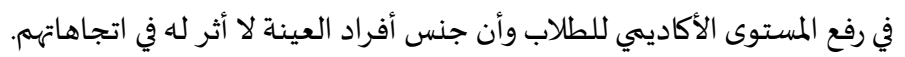

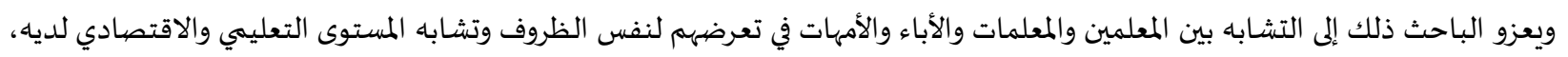

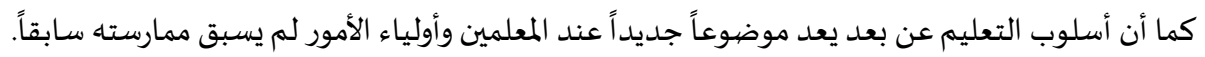

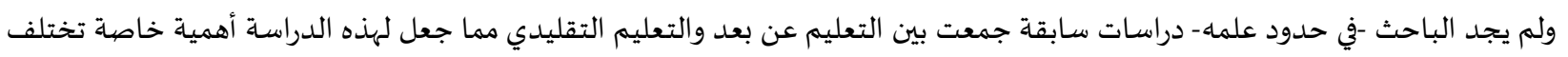
عن غيرها من الدراسات المتعلقة باستخدام التعليم عن بعد والتعليم التقليدي. 5.4 التوصيات: في ضوء النتائج التي توصلت إليها الدراسة، يوصي الباحث بالآتي:

تشجيع المعلمين على التعرف واستخد ام إستراتيجيات التعليم عن بعد في العملية التدريسية. تضمين المناهج الدراسية أنشطة تراعي إستراتيجيات التعليم عن بعد المعتمدة على المعلمين والطلاب في معظم الأحيان لتنمية هذا الجانب لديهم. 
إدخال مواد دراسية تربط بين المادة التعليمية المراد تدريسها وطرق وإستراتيجيات الدمج بينها وبين التعليم التقليدي من جانب والتعليم عن بعد من جانب أخر. إيجاد الكفاءات وتدريب كادر المعلمين على استخد ام إستراتيجيات التعليم عن بعد أكثر وتوفير الوسائل اللازمة لذلك. تعزيز دور أولياء الأمور وإكسابهم المهارات اللازمة التي من شأها رفع قدرتهم على استخدام الوسائل الإلكترونية للتعليم. إجراء ورش عمل وفيديوهات توعوية تبرز أهمية التعليم عن بعد تكون موجهة إلى أولياء الأمور بصورة مباشرة.

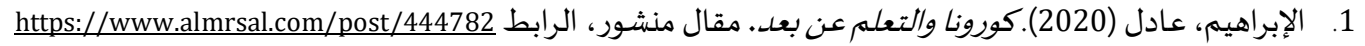
2. الأشي، ألفت بنت عبدالعزيز (2021). الممارسات التربوية للوالدين في التعليم عن بعد للمرحلة الابتد ائية وعلاقتها بكفاءة إدارة الوقت و الجهـد -

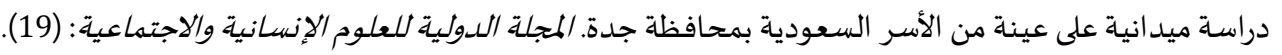

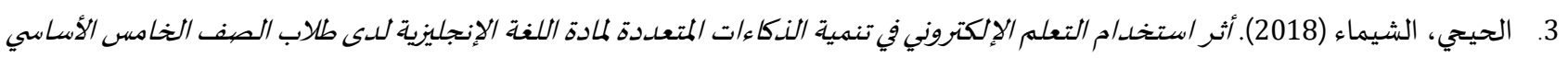
بالعاصمة /عمان. (رسالة ماجستير غير منشورة)، جامعة الشرق الأوسط، عمان، الأردن.

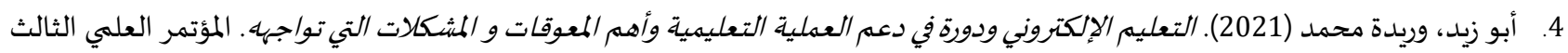

لكلية التربية العجيلات، جامعة الزاوية.

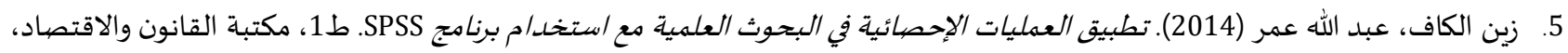

$$
\text { الرياض: المملكة العربية السعودية. }
$$

6. سامي، إيمان (2019). الفرق بين التعليم التقليدي والتعليم الحسلديث. مقال منشودرو، الرابط https://www.almrsal.com/post/841632\#\%D8\%B3\%D9\%84\%D8\%A8\%D9\%8A\%D8\%A7\%D8\%AA \%D8\%A7\%D9\%84\%D8\%AA\%D8\%B9\%D9\%84\%D 9\%8A\%D9\%85 \%D8\%A7\%D9\%84\%D8\%AD\%D8\%AF\%D9\%8A\%D8\%AB

7. الشكعة، هناء مصطفى فارس (2016). أثر استراتيجيتي التعلم المددمج والتعلم المعكوس في تحصيل متعلمين الصف السابع في مادة العلوم

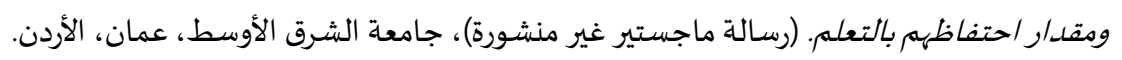

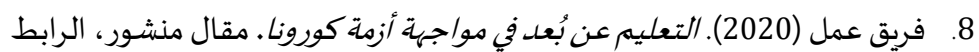

https://ar.zenit.org/2020/03/26/\%d8\%a7\%d9\%84\%d8\%aa\%d8\%b9\%d9\%84\%d9\%8a\%d9\%85-\%d8\%b9\%d9\%86-\%d8\%a8\%d9\%8f\%d8\%b9\%d8\%af\%d9\%81\%d9\%8a-

\%d9\%85\%d9\%88\%d8\%a7\%d8\%ac\%d9\%87\%d8\%a9\%d8\%a3\%d8\%b2\%d9\%85\%d8\%a9\%d9\%83\%d9\%88\%d8\%b1\%d9\%88\%d9\%86\%d8\%a7/ 9. الفهيد، تركي بن فيصل بن تركي (2015). واقع استخدام التعليم الممدمج في تدريس العلوم الطبيعية في الممحلة الثانوية من وجهة نظر مشرفي

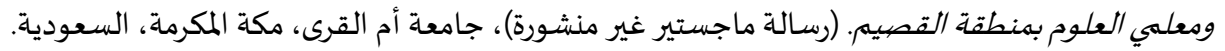

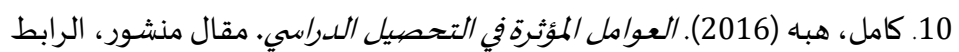

https://mawdoo3.com/\%D8\%A7\%D9\%84\%D8\%B9\%D9\%88\%D8\%A7\%D9\%85\%D9\%84 \%D8\%A7\%D9\%84\%D9\%85\%D8\%A4\%D8\%AB\%D8\%B1\%D 8\%A9 \%D9\%81\%D9\%8A \%D8\%A7\%D9\%84\%D8\%AA\%D8\%AD\%D8\%B5\%D9\%8A\%D9\%84 \%D8\%A7\%D9\%84\%D8\%AF\%D8\%B1\%D8\%A7\%D8\%B 3\%D9\%8A

11. المجالي، وفاء (2019). درجة استخلدام إستراتيجية التعلم الملدمج للى معلهي الممحلة الأساسية في لواء وادي السير. (رسالة ماجستير غير

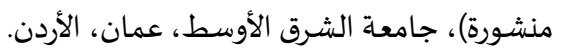

12. مرشود، جمال محمد (2016). صعوبات تطبيق التعلهم الملدمج في مدارس وكالة الغوث الدولية في شمال فلسطين من وجهات نظر المديرين. مجلة جامعة الخليل للبحوث: 11 (1): 77-96. 13. النحال، عادل ناظر وعقل، مجدي سعيد (2016). أثر توظيف إستراتيجية المشاريع الإلكترونية في تنمية مهارات تصريمر مواقع الويب التعليمية.

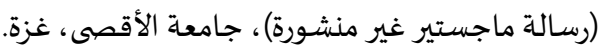

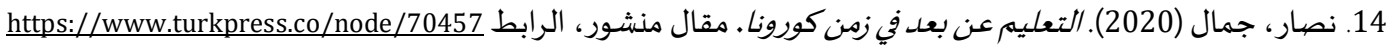

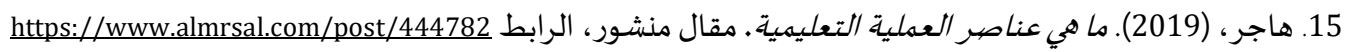

1. AL-Hadhoud, N.A., \& AL-Hattami, A.AL. (2017). Blended Learning and the Obstacles to its Implementation. International journal of Pedagogical Innovations, 5(1): 72-89. https://doi.org/10.12785/ijpi/050106

2. Cracraft, L. (2015). Effect of Blended Learning on Student's Percent Increase in Assessment Scores. (unpublished Master Thesis), Northwest Missouri State University, Columbia, Missouri: USA

3. Martinsen, B.W. (2017). The Learning to Academic Achievement. Journal of Human Science, 14(1): 308-320 
المجلة الدولية للدراسـات التربوية والنفسية

International Journal of Educational \& Psychological Studies (EPS)

Journal Homepage: https://www.refaad.com/views/EPSR/Home.aspx

www.refaad.com

ISSN: 2520-4149 (Online) 2520-4130 (Print)

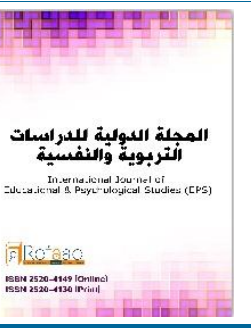

\title{
Attitudes of parents and teachers of the first three grades towards the use of distance education and traditional education in Jordan (Comparative study)
}

\section{Marwan Abdullah Al-Awayshah}

AlBalqa Applied University, Jordan Mrwan84@bau.edu.jo

Received : 21/6/2021 Revised : 12/7/2021 Accepted : 25/7/2021 DOI : https://doi.org/10.31559/EPS2021.10.3.3

\begin{abstract}
This study aimed to reveal the attitudes of parents and teachers of the first three grades towards the use of distance education and traditional education in Jordan. The study sample consisted (157) male and female teachers, (235) parents of students and parents towards the feasibility of distance education and traditional education. After adjusting and applying them to the study sample, the results showed that there are moderate-level trends in the research sample towards the use of e-learning and its feasibility in raising the academic level of students. There are low-level trends towards the feasibility of using traditional education in raising the academic level of class students. The results also showed that there were no statistically significant differences at the significance level $(\alpha \leq 0.05)$ in the attitudes of parents and teachers of the first three grades when using distance education due to the gender variable, and there were no statistically significant differences at the significance level $(\alpha \leq 0.05)$ in the attitudes of parents and teachers of the first three grades towards the use of traditional education due to the gender variable.

The researcher recommended that school curricula include activities that take into account distance education strategies and enhance the role of parents and teachers through rehabilitating and training them in various ways to identify and practice this type of education.
\end{abstract}

Keywords: Distance education; Traditional education; Attitudes.

\section{References:}

1. Alashy, Alft Bnt 'bdal'zyz (2021). Almmarsat Altrbwyh Llwaldyn Fy Alt'lym 'n B'd Llmrhlh Alabtda'yh W'laqtha Bkfa'h Edart Alwqt W Aljhd - Drash Mydanyh 'la 'ynh Mn Alasr Als'wdyh Bmhafzt Jdh. Almjlh Aldwlyh Ll'lwm Alensanyh Walajtma'yh: (19).

2. Alebrahym, 'adl (2020). Kwrwna Walt'lm 'n B'd. Mqal Mnshwr, Alrabt https://www.almrsal.com/post/444782

3. Alfhyd, Trky Bn Fysl Bn Trky (2015). Waq' Astkhdam Alt'lym Almdmj Fy Tdrys Al'lwm Altby'yh Fy Almrhlh Althanwyh Mn Wjhh Nzr Mshrfy Wm'lmy Al'lwm Bmntqt Alqsym. (Rsalh Majstyr Ghyr Mnshwrh), Jam't Am Alqra, Mkh Almkrmh, Als'wdyh.

4. Fryq 'ml (2020). Alt'lym 'n Bu'd Fy Mwajhh Azmh Kwrwna. Mqal Mnshwr, Alrabt https://ar.zenit.org/2020/03/26/\%d8\%a7\%d9\%84\%d8\%aa\%d8\%b9\%d9\%84\%d9\%8a\%d9\%85-\%d8\%b9\%d9\%86\%d8\%a8\%d9\%8f\%d8\%b9\%d8\%af-\%d9\%81\%d9\%8a-

\%d9\%85\%d9\%88\%d8\%a7\%d8\%ac\%d9\%87\%d8\%a9\%d8\%a3\%d8\%b2\%d9\%85\%d8\%a9\%d9\%83\%d9\%88\%d8\%b1\%d9\%88\%d9 $\% 86 \% \mathrm{~d} 8 \% \mathrm{a} 7$

5. Hajr, (2019). Ma Hy 'nasr Al'mlyh Alt'lymyh. Mqal Mnshwr, Alrabt https://www.almrsal.com/post/444782

6. Alhyhy, Alshyma' (2018). Athr Astkhdam Alt'lm Alelktrwny Fy Tnmyt Aldka'at Almt'ddh Lmadh Allghh Alenjlyzyh Lda Tlab Alsf Alkhams Alasasy Bal'asmh /'man. (Rsalt Majstyr Ghyr Mnshwrh), Jam't Alshrq Alawst, 'man, Alardn.

7. Kaml, Hbh (2016). Al'waml Alm'thrh Fy Althsyl Aldrasy. Mqal Mnshwr, Alrabt

https://mawdoo3.com/\%d8\%a7\%d9\%84\%d8\%b9\%d9\%88\%d8\%a7\%d9\%85\%d9\%84 \%d8\%a7\%d9\%84\%d9\%85\%d8\%a4\%d8\%ab \%d8\%b1\%d8\%a9 \%d9\%81\%d9\%8a \%d8\%a7\%d9\%84\%d8\%aa\%d8\%ad\%d8\%b5\%d9\%8a\%d9\%84 \%d8\%a7\%d9\%84\%d8\%af\%d8 $\% \mathrm{~b} 1 \% \mathrm{~d} 8 \% \mathrm{a} 7 \% \mathrm{~d} 8 \% \mathrm{~b} 3 \% \mathrm{~d} 9 \% 8 \mathrm{a}$

8. Almjaly, Wfa' (2019). Drjt Astkhdam Estratyjyh Alt'lm Almdmj Lda M'lmy Almrhlh Alasasyh Fy Lwa' Wady Alsyr. (Rsalt Majstyr Ghyr Mnshwrh), Jam't Alshrq Alawst, 'man, Alardn. 
9. Mrshwd, Jmal Mhmd (2016). S'wbat Ttbyq Alt'lm Almdmj Fy Mdars Wkalt Alghwth Aldwlyh Fy Shmal Flstyn Mn Wjhat Nzr Almdyryn. Mjlt Jam't Alkhlyl Llbhwth: 11 (1): 77-96.

10. Alnhal, 'adl Nazr W'ql, Mjdy S'eyd (2016). Athr Twzyf Estratyjyh Almshary' Alelktrwnyh Fy Tnmyt Mharat Tsmym Mwaq' Alwyb Alt'lymyh. (Rsalt Majstyr Ghyr Mnshwrh), Jam't Alaqsa, Ghzh.

11. Nsar, Jmal (2020). Alt'lym 'n B'd Fy Zmn Kwrwna. Mqal Mnshwr, Alrabt https://www.turkpress.co/node/70457

12. Samy, Eyman (2019). Alfrq Byn Alt'lym Altqlydy Walt'lym Alhdyth. Mqal Mnshwr, Alrabt

https://www.almrsal.com/post/841632\#\%d8\%b3\%d9\%84\%d8\%a8\%d9\%8a\%d8\%a7\%d8\%aa_\%d8\%a7\%d9\%84\%d8\%aa\%d8\%b9\%d9\%84\%d9\%8a\% d9\%85\%d8\%a7\%d9\%84\%d8\%ad\%d8\%af\%d9\%8a\%d8\%ab

13. Alshk'h, Hna' Mstfa Fars (2016). Athr Astratyjyty Alt'lm Almdmj Walt'lm Alm'kws Fy Thsyl Mt'lmyn Alsf Alsab' Fy Madt Al'Iwm Wmqdar Ahtfazhm Balt'Im. (Rsalt Majstyr Ghyr Mnshwrh), Jam't Alshrq Alawst, 'man, Alardn.

14. Abw Zyd, Wrydh Mhmd (2021). Alt'lym Alelktrwny Wdwrh Fy D'm Al'mlyh Alt'lymyh Wahm Alm'wqat W Almshklat Alty Twajhh. Alm'tmr Al'Imy Althalth Lklyt Altrbyh Al'jylat, Jam't Alzawyh.

15. Zyn Alkaf, 'bd Allh 'mr (2014). Ttbyq Al'mlyat Alehsa'yh Fy Albhwth Al'lmyh M' Astkhdam Brnamj Spss. T1, Mktbt Alqanwn Walaqtsad, Alryad: Almmlkh Al'rbyh Als'wdyh. 